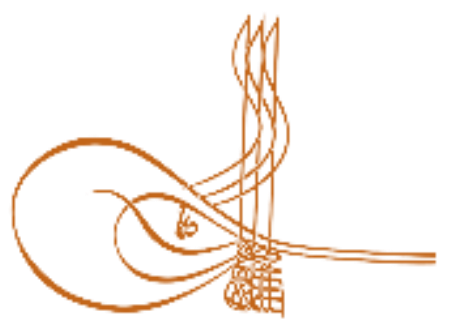

www.turkishstudies.net/turkishstudies
Turkish Studies

eISSN: $1308-2140$

Research Article / Araștırma Makalesi

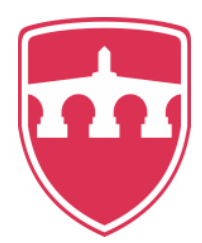

INTERNATIONAL

BALKAN

UNIVERSITY

Sponsored by IBU

\title{
Destek Eğitim Odalarında Verilen Eğitimin Okul Öncesi Kaynaştırma Öğrencilerinin Gelişimine Olan Etkisinin İncelenmesi*
}

\author{
Investigation of the Effect of the Education Given in the Support Training Rooms on the \\ Development of Preschool Inclusion Students
}

\author{
Kamil Arif Kırkıç** - Abdulhalit Sayan ${ }^{* * *}$
}

\begin{abstract}
This research aims to examine the development of students who receive inclusive education in schools providing early childhood education. The development of inclusion students, who are educated in the support rooms, and the students participating in the inclusive education, other than the support rooms, have been examined with the quantitative research model. Using the experimental design, one of the designs of the quantitative model, the effect of training in the support rooms on the development of 40 students who participated in the research with pretest-posttest measurements was investigated. The data was collected with the study carried out in the 2017-2018 academic year in the preschool education institutions in Küçükçekmece district within the Ministry of National Education (MoNE). The data were collected from 20 students in the experimental and 20 students in the control groups. The development of the inclusion students participating in the study was monitored with an evaluation form developed by the Guidance Research Center (GRC) experts. One month after the school starting date the levels of development in various fields determined by teachers about the students in the experimental and control groups were used as pretests. The posttest was the educational evaluation form filled by teachers one month before the school ended. The pretest-posttest measurements obtained were analyzed with statistical program. While analyzing the data, related and independent groups t-tests were used. The results of the study were significantly higher for inclusion students who were trained in the support room than inclusion students without support room education in terms of the development of the psychomotor, cognitive, language and self-care skills. There was no significant difference in the social-emotional development dimension between the experimental and control groups.
\end{abstract}

\footnotetext{
* Bu makale birinci yazarın danışmanlığında ikinci yazar tarafından tamamlanmış olan yükek lisans tezinden hazırlanmıştır.

** Dr. Öğr. Üyesi, İstanbul Sabahattin Zaim Üniversitesi, Eğitim Fakültesi, Eğitim Bilimleri Bölümü

Asst. Prof. Dr., Istanbul Sabahattin Zaim University, Faculty of Education, Depatrment of Educational Sciences

ORCID 0000-0002-8902-437X

kamil.kirkic@izu.edu.tr

**** Okul Müdürü, MEB

School Principal, MoNE

ORCID 0000-0002-8078-4276

halitsayan@gmail.com

Cite as/ Atıf: Kırkıç, K. A., Sayan, A (2020). Destek eğitim odalarında verilen eğitimin okul öncesi kaynaştırma öğrencilerinin gelişimine olan etkisinin incelenmesi, Turkish Studies, 15(2), 1121-1136. https://dx.doi.org/10.29228/TurkishStudies.29348

Received/Geliş: 04 August/Ağustos 2019

Accepted/Kabul: 25 April/Nisan 2020

Copyright $\subset$ MDE, Turkey

Checked by plagiarism software

Published/Yayın: 30 April/Nisan 2020

CC BY-NC 4.0
} 


\section{Structured Abstract: Introduction}

The main objective of the education is to educate individuals as constructive, positive and productive individuals who know their responsibility to belong to a person and structure that is mentally, morally, spiritually and emotionally harmonious and well developed. It should be structured with the principle that individuals in need of special education should be educated in pre-schools with their peers in a learning environment, which is suitable for them, and that they should take advantage of this education.

Education, which is the most fundamental right, should be given to every child, and the way of completing the education process should be clear. Each individual has the right to education according to interest, ability, and need for learning. By highlighting this feature and the range of needs, educational modeling should be redesigned, and educational programming should be put forward. Those in need of special education should continue formal education. These schools should be capable of revealing their needs and should take into consideration an individual-centered learning environment.

As a part of the society, children in need of special needs have the most natural right to go through the socialization process with their peers in the preschool period. It is known that it is of great importance that these children receive an education with their peers. Since the skills acquired in the preschool period will be the basis of life, the quality of education received by these children in the school is of great importance.

However, the quality environment that can provide education to children with special needs is a topic that has been studied and discussed for years. The common idea is; directing children in need of special needs to education on the platform where the limitation is minimized. Students with learning disabilities can receive inclusive education in the same class with their normally progressing peers (Dikici Sığırtmaç and Deretarla Gül, 2012).

Turkey also made in inclusive preschool education are inadequate. Support training room system has been developed to provide inclusion students to get a better education. At this point, this research was planned to attract interest in mainstreaming education and following the progress of mainstreaming students receiving instruction in the support training room.

\section{Method}

In this part of the research, research model, working group, data collection tools, data collection process, and research process are discussed. The quantitative research method was used as the research model in the study. The experimental method was used as the research method. Quantitative research emerged as a result of social science. Quantitative analysis is aimed at achieving precise and generalizable results by using numerical data (Gürbüz and Şahin, 2016). In the model with pre-test and post-test control groups, there are two groups formed by random assignment. One of them is used as an experimental and the other as a control group. Measurements are performed before and after the operation in both groups.

In this study, it was aimed to observe the development of the students who were educated in the support education room to mainstream students in the preschool period and to ensure that the teachers' development of the students at the end of the semester was determined and transferred. In this study, a questionnaire was applied in quantitative techniques (Karasar, 2005)

\section{Findings, Discussion, and Results}

At the end of the education, a significant difference was found between the students' disability level scores in favor of the students who were given support education. Psychomotor skills, cognitive skills, selfcare skills, and students' inadequacy level subscales can be said to have achieved significant success in the instruction given in the support training room. Although there is no significant difference between preschool mainstreaming students who receive support training in language development, social and emotional development sub-dimensions, it can be considered that the education given in the support training room is also successful because the average score of the students receiving support training in both sub-dimensions is higher. Similarly, Ünay (2012) found that mathematics education is given to mainstreaming students increased mathematics achievement significantly compared to general education class, and teachers stated that selfefficacy of mainstreaming students increased slightly with the training provided in individual support room. Kutluca Canbulat (2010) concluded that support education had achieved great success in terms of language development, psychomotor development, social skills, emotional aspect, and cognitive skills. Ünal (2008) 
found that the Turkish and mathematics courses given in the support training room reached the desired result successfully. Deniz (2018) stated that the majority of teachers did not make any arrangements in the content of instruction for mainstreaming students; organizers concentrate on assisted work, activity simplification, activity preparation for students, and content determination; other studies have reached the conclusion that they do a limited number of these results can be considered to have emerged. In contrast, Kış (2013) concluded that the inclusive education done in support training rooms applications failed.

Keywords: Instructional methods, development, preschool education, support education room, inclusive education

Öz: Bu araştırma erken çocukluk eğitimi veren okullarda kaynaştırma eğitimi alan öğrencilerin gelişimlerini incelemeyi amaçlamaktadır. Destek odalarında eğitim alan kaynaştırma öğrencileri ile destek odaları dışında kaynaştırma eğitimine katılan öğrencilerin gelişimleri nicel araştırma modeli ile incelenmiştir. Nicel modelin tasarımlarından deneysel tasarım kullanılarak, öntest-sontest ölçümleriyle araştırmaya katılan 40 öğrencinin gelişimine destek odalarında eğitim alınmasının etkisi araştırılmış̧ır. Milli Eğitim Bakanlığı'nın (MEB) bünyesinde Kü̧̈ükçekmece ilçesinde bulunan okul öncesi eğitim kurumlarında 2017-2018 öğretim yllında yapılan çalışma ile veriler toplanmıştır. Deney ve kontrol grubunda bulunan 20'şer öğrenciden veriler toplanmıştır. Çalışmaya katılan kaynaştırma öğrencilerinin gelişimleri Rehberlik Araşsırma Merkezi (RAM) uzmanlarınca geliştirilmiş olan değerlendirme formu ile izlenmiştir. Okula başlama tarihinden bir ay sonra deney ve kontrol gruplarındaki öğrenciler hakkında öğretmenler tarafindan belirlenen çeşitli alanlardaki gelişim düzeyleri öntest olarak kullanılmıştır. Sontest ise okulun sona ermesinden bir ay öncesinde öğretmenler tarafından düzenlenen eğitsel değerlendirme formu olmuştur. Elde edilen öntest-sontest ölçümleri istatistiksel program ile analiz edilmiştir. Veriler çözümlenirken ilişkili ve bağımsız gruplar t-testi kullanılmışırı. Çalışmanın sonuçları destek odasında eğitim alan kaynaştırma öğrencilerinin psikomotor, bilişsel, dil ve öz bakım becerilerinin gelişimi, sadece kaynaştırma eğitimi alan öğrencilerin bu becerilerinin gelişiminden anlamlı derecede yüksek olmuştur. Deney ve kontrol grupları arasında, sosyal-duygusal gelişim boyutunda anlamlı düzeyde bir fark oluşmamıştır. Sosyal, duygusal ve dil gelişimi alt boyutlarında destek eğitimi alan ve almayan 0-6 yaş kaynaştırma öğrencileri arasında önemli bir farklılık olmasa da her iki alt boyutta destek eğitimi alan ögrencilerin puan ortalamalarının yüksek olduğu ve buna bağlı olarak da bu eğitimin başarıya ulaştı̆̆ düşünülebilir.

Anahtar Kelimeler: Öğretim yöntemleri, gelişim, okul öncesi eğitimi, destek eğitim odası, kaynaştırma eğitimi

\section{Giriş}

Bireyin zihnen, ahlâken, manen, sezgileri güçlü olarak ve sağlıklı bir süreçte yetişmiş bir insana dönüştürülmesi ve mesuliyetinin farkında olan, pozitif bakış açısına sahip, kazanılmış kişiler olarak yetiştirilmesi eğitimin asıl amacıdır. Yaşıtlarından daha farklı bir öğretim biçimine (özel eğitime) gereksinimi olan çocukların, temel eğitimden bağımsız olarak aynı yaş grubuna sahip çocuklarla birlikte, onlara uygun ortamın sağlanacağı öğretim) ortamlarında onları merkeze alan eğitim görmeleri ve bu eğitim hakkından yararlanmaları öncelikli haklarıdır.

Evrensel hak olarak her çocuk yaşamı boyunca eğitim alma önceliğine sahiptir ve bu eğitimi eksiksiz bitirme hakkı her çocuğa açık olmalıdır. Her bireyin, kendine özgü hususlarda; ilgisine, yeteneğine ve öğrenim gereksinimine göre öğrenim alabilme hakkı bulunmaktadır (Illköğretim ve Eğitim Kanunu, 1961). Bu hususları göz önüne alarak, eğitim ve öğretim çevreleri tekrardan tasarlanmalı ve yeni eğitimsel programları geliştirilmelidir. Özel eğitime muhtaç olanlar da özel eğitime ihtiyacı olmayan öğrenciler gibi örgün eğitime devam edebilmelidir. Özel eğitime muhtaç olan ve olmayan öğrencilerin birlikte öğrenim görebileceği okullar, yaşıtlarından daha farklı bir öğretim biçimine, özel eğitime gereksinimi olan çocukların ihtiyaçlarını karşılayabilecek seviyede olmalıdır. Böylelikle özel eğitime ihtiyacı olan öğrencilerin "bireyi merkeze alan" eğitim ortamlarında yetiştirilmelerine imkân tanımalıdır. 
Kişinin hayatında etkin alıcı olduğu ve gelişimini belirleyen önemli bir dönem bulunmaktadır. Kritik dönem şeklinde ifade edilen bu süreçte ihtiyaç duyulan bilgileri elde edemeyen ve becerileri kazanamayan birey için sonraki dönemlerde bu eksikliğin telafisi zorlaşmakta ve bu durumda da bireyin gelişimi olumsuz etkilenebilmektedir.

Kişinin, doğumdan itibaren ilk altı yıl içerisindeki büyüme sürecindeki fark edilir derecede ciddi ve aktif gelişim sahalarından biri de vücudun farklı kaslarının kontrol gelişimini sağlamasına yardımcı olacak süreç hareket gelişimidir (Ilgar, 2006: 16). Yüksek risk taşıyan bu döngüde zaman yönetimi mühimdir. Çocuğun gelişimi için önemli olan dönemlerde gereken destek çocuklara sağlanmadığı ve elverişli ortamlar sağlanmaması durumunda beklenen ilerlemenin beklenen düzeyde gerçekleşmemesi veya geçici olarak durması söz konusudur. Çocuk gelişim uzmanları, psikologlar ve eğitimciler, çocuklar için psiko-sosyal gelişim, zihin gelişimi ve dil gelişiminde önemli olan zaman diliminin temel eğitim öncesi olduğu ve bu dönemde kazanılan tutumun yaşam boyunca sürekliliğini devam ettirdiğini ifade etmektedir (Dağlığlu, 2014).

Hayvanların eğitime ihtiyaç duymadan yaşayabilmelerine ve kısmen eğitilebilir olmalarına karşın, canlı varlıklar arasında eğitime ihtiyacı en belirgin olan ve eğitilebilir olan insanoğludur. Çünkü insanoğlu gelişmiş sinir yapısı, mükemmel beden yapısı ile doğmaktadır. Üstün bir öğrenme yeteneğine ve öğrenmesini sağlayacak her türlü donanıma sahip olarak dünyaya gelmektedir. Ancak eğitilmesi ile insanca yaşayabilmesi mümkün olabilmektedir. (Ilgar, 2006: 16). Öncelikle 0-6 yaş arası çocukların ilk 4 yıllık ilkokul eğitim sürecine başlamadan önce yaşadıkları ciddi döneme bakıldığında süratli bir gelişim yaşadıkları, bu süreçte bilinen " $0-6$ yaş için tasarlanmış okul öncesi eğitim" fark edilmesi gereken hassasiyete sahiptir. Söz konusu dönemdeki çocuklar, gelişim özelliklerini, yeteneklerini, beğendikleri taraflarını ve gereksinimlerini tespit edemediklerinden, duygularını ve söylemek istediklerini olması gerektiği gibi anlatamadıkları dikkate alınırsa onlar için rol model olacak eğitimcilerin ve aile bireylerinin bilinçli ve dikkatli davranmaları esastır (MEGEP, 2011).

Yaşıtlarından daha farklı bir öğretim biçimine, özel eğitime, gereksinimi olan çocukların da toplumun bir üyesi oldukları düşünülürse, 0-6 yaş arası dönemde toplum içinde var olma gelişimini kendi yaşıtlarıyla gerçekleştirmeleri onların en doğal hakkıdır. Okul öncesi dönemde edinilen bilgiler ve başarabilme duygusu hayat döngüsünün ilk adımlarına karşılık geldiğinden, bu bireylerin okullarında alacakları eğitimin niteliği de oldukça değerlidir.

Diğer çocuklardan daha farklı bir gereksinime ihtiyacı olan çocuklar, özel gereksinime ihtiyacı olmayan diğer çocuklar gibi sınırlamaların en aza indirildiği platformlarda eğitim görmelidir. Dolayisıyla bunu başarabilmenin bir yolu da özel gereksinimi olan öğrencinin doğal gelişim içinde olan yaşıtlarıyla birlikte aynı öğrenme ortamında kaynaştırma eğitimi almasıdır (Dikici Sı̆̆ırtmaç ve Deretarla Gül, 2012). Kaynaştırma eğitimi, daha farklı bir öğretim biçimine gereksinimi olan çocukların doğal gelişim gösteren yaşıtları ile benzer sınıfta destek eğitimini benimseyen aktivitelerden beraber yararlanmasıdır. Bu eğitim işleyişi, devlet, özel ve/veya $0-6$ yaş arası eğitim döneminden başlayıp, ilk, orta veya hizmet içi eğitim yapılarından alınması gereken bir eğitim işleyişini içermektedir (Özel Eğitim Hizmetleri, 2018).

Normal sınıflarda eğitimine devam etmekte olan özel gereksinime sahip çocuklar yetersiz kaldıkları derslerde veya fazladan çaba göstermesi beklenen alanlardaki (örneğin, dilsel, matematiksel vb) eksikliklerini giderebilmek amaciyla destek eğitim odasında kendilerine uygun bilgileri ve becerileri edinirler. Destek eğitimi sınıfında; konuya hakim öğretmenlerden ya da özel eğitimciler tarafından birebir veya tüm sınıfa hitaben eğitim verilir. (Batu \& Kırcaali İftar, 2006).

Kaynaştırma öğrencilerinin bulundukları ortamdan farklı, destek eğitimi bölümlerinde gerekli görülen eğitimi almaları, gereksinim duydukları ihtiyaçların giderilmesi yönünde uygun şartlar öngörmekte ve öğrencinin hayatında yaşayacağı temel ve özel yatkınlıklarının ilerlemesine faydası olabilmektedir. 
Destek eğitimi sınıfında, verilen bilgilerin doğru noktaya ulaşabilmesi için kaynaştırma eğitimi öğrencisinin bulunduğu sinıfta eğitim veren öğretmenler birlikte hareket etmelidir. Kaynaştırma öğrencisinin aldığı destek eğitimi ile sınıfta verilen eğitimin aynı noktada olması esastır (Batu \& Kurcaali İftar, 2006).

Okullarda yapılan bu çalışma etkili bir zemine bağlı eğitim çalışmasıdır. Bu eğitime tabi tutulan öğrenci kendi beceri durumuna göre bazı dersleri sınıf ortamında kolaylıkla alır. Zorlandığı dersleri de yine destek eğitim odasında gereklilik durumuna bağlı olarak özel öğretmeni, sınıf öğretmeni ya da yardımcı öğretmeni tarafindan alır (Çorlu ve Ersoy, 2013).

Türkiye'de 0-6 yaş arası dönemde gerçekleştirilen kaynaştırma eğitimi verimsiz kalabilmektedir. Kaynaştırma öğrencilerinin daha kaliteli bir eğitime ihtiyacı olduğu için destek eğitimi sisteme eklenmiş ve zenginleştirilmiştir. Kaynaştırma eğitiminin önemini belirtmek ve destek eğitim odasında eğitim gören öğrencilerin durumunu izlemek ve sonucu anlamak için bu araştırma yapılmıştır. Söz konusu duruma bakıldığı zaman, amaç; yaşıtlarından daha farklı bir eğitim gereksinimi olan çocukların toplum içinde birey olarak kendi geleceğini kurması ve hayatına yön vermesidir. Bu çocukların, sistem düzgün çalıştığı sürece doğal gelişim gösteren yaşıtları ile aynı ortamda olmalarını sağlamaktır. İhtiyaç duydukları eğitim ve öğretimi maksimum noktada sağlayacak şekilde hazırlamaktır. Bu eğitim işleyişine istinaden yapılan aktiviteler, devlet ya da özel okulları temel alan çalışmalar; 0-6 yaş arası eğitim döneminden başlayıp, ilköğretimden ortaöğretime kadar uzanan ve tüm yaygın eğitimi kapsayan işleyiştir (Özel Eğitim Hizmetleri, 2018).

Destek eğitim ile ilgili anlatılmak istenen; kaynaştırmadan faydalanarak eğitim-öğretim ihtiyacı karşılanan kişiler ile farklı becerilere sahip öğrencilerin gereksinimleri yönünde destek vermek için planlanan aktivite alanlanıdır (Özel Eğitim Hizmetleri, 2018). Özel eğitim ihtiyacı duyan çocukların özellikle erken çocukluk eğitimi döneminde niteliği yüksek ve bu çocukların ihtiyaçlarına cevap verebilecek şekilde düzenlenmelidir. Böyle tasarlanarak uygulanan destek süreci, öğrencilerin olumlu öğrenme ürünlerine sahip olmalarını sağlamaktadır (Barton \& Joseph, 2015; Espinosa, 2002). Erken çocukluk eğitimi döneminde özel eğitime ihtiyaç duyan çocuklara nitelikli bir kaynaştırma eğitimi verilmesi bütün çocuklar için yararlı olmakla birlikte özel eğitime gereksinim duyan çocuklarda pek çok olumlu öğrenme ürününe ulaşılmasını sağlamaktadır (Justice, Logan, Lin \& Kaderavek, 2014; Strain \& Bovey II, 2011).

\section{Araştırmanın Amacı}

Çalışmanın amacı destek eğitimi alan kaynaştırma öğrencileri ile bu eğitimi alamayan kaynaştırma öğrencilerinin, Eğitsel Değerlendirme Formundan aldıkları puanlara göre bu iki grup arasında fark bulunmakta midır?, sorusuna yanıt aramaktır.

\section{Araştırmanın Önemi}

İnsanlar birbirlerinden farklı yaratılmıştır. Fiziksel engeller (kalça çıkığı, uzuv kaybı, beyin felci vb) ve zihinsel engeller (öğrenme güçlüğü, disleksi vb.) özel eğitime gereksinimi olan öğrenciler açısından farklılıklar oluştursa da, bu farklılıklar belli sınırlar içinde olduğundan, özel gereksinimi olan bireyler de genel eğitim hizmetlerinden yararlanabilirler. Ancak örgün eğitim hizmetleri daha genel tasarlandığından, özel gereksinimi olan öğrenciler için ihtiyaçlarını gidermek üzere özel eğitim süreci oluşturulmalı ve uygulanmalıdır (Kırcaali İftar, 1998: 57).

0-6 yaş arası çocuklar öğrenmeye meraklı, çevresini gözlemleyen, soran sorgulayan ve deneyerek kendi doğrusuna ulaşmak isteyen bireylerdir. Bu dönemin özelliklerine bağli olarak 0-6 yaş arası çocukların soyut kavramları anlamlandıramayacakları için bunların somut olarak onlara sunulmas1 gerekmektedir (Ültay ve Ültay, 2016).

Ülkemizde ilk olarak 2006 ve sonra 2013 yıllarında 0-6 yaş aralığı için tasarlanmış öğretim programlarında bahsedilen durum göz önüne alınmıştır. Öğretmenlerin, 0-6 yaş arası eğitim 
sınıflarında kaynaştırma eğitimi ile ilgili farklı gereksinimleri olan çocukların durumu ve faaliyetlerin bu çocukları da içine alan bir sistem ile ilgili bilgilendirildiği izlenmektedir (MEB, 2008; MEB, 2013).

İnsan tekâmülünün en belirgin hususu bireysel olarak birbirinden ayrı özelliklere sahip olmasıdır. Bu durumu aile çocuklarında, eğitici öğrencilerinde izleyebilir. Bu farklılık belirli bir düzeye kadar çocuğun normal bir eğitim almasına engel olmaz. Ama bazı durumlarda özel muameleye ihtiyaç duyulabilir (Kırcaali İftar,1998: 22).

Yapılan bu çalışma ile 0-6 yaş arası eğitimde kaynaştırma öğrencilerinin destek eğitim sınıflarında almış oldukları eğitim çalışmaları yorumlanmıştır. Bu yoruma bağlı olarak hali hazırda verilen destek eğitimlerinin özelliğinin göz önüne alınması hedeflenmiştir. Buna göre 0-6 yaş arası eğitimin kaynaştırma öğrencilerine destek eğitimi sağlanabilmesi adına mevcut uygulamada bulunan eksiklilerin ve yanlışların tespit edilmesi, bu eksiklerin giderilmesi ve bulunan yanlışların düzeltilmesi olasılık dâhilindedir.

Çalışmanın amacı destek eğitim odasında eğitim alan ve almayan kaynaştırma öğrencilerinin Eğitsel Değerlendirme Formu puanlarına göre, varsa, farklılaştıkları alanları belirlemektir. Araştırmanın alt problemleri aşağıda belirtilmiştir:

1.Okul öncesi eğitiminde destek odasında kaynaştırma eğitimi (DOKE) alan öğrencilerin Eğitsel Değerlendirme Formu (EDF) öntest -sontest puanları karşılaştırtıldığında aralarında anlamlı fark bulunmakta midir?

2.Okul öncesi eğitiminde sadece kaynaştırma eğitimi alan (SaKE) öğrencilerin öntest sontest puanları karşılaştırtıldığında aralarında anlamlı fark bulunmakta mıdır?

3. Okul öncesi eğitiminde destek odasında kaynaştırma eğitimi (DOKE) alan öğrenciler ile sadece kaynaştırma eğitimi alan (SaKE) öğrencilerin Eğitsel Değerlendirme Formu (EDF) sontest puanları karşılaştırtıldığında aralarında anlamlı fark bulunmakta mıdır?

\section{Yöntem}

Yöntem bölümünde araştırmanın deseni/modeli, çalışmada yer alan katılımcıların oluşturduğu çalışma grubu ve veri elde etmek için kullanılan araçlar ile toplanan verilerin nasıl analiz edileceğini açıklayan veri analiz tekniklerine yer verilmiştir.

Çalışma deseni olarak nicel araştırma modelinin deneysel tasarım deseni kullanılmıştır. Deneysel çalışmalar neden-sonuç ilişkisini ortaya koyabilmek ve benzeri şartlara genellemeyi hedeflemektedir (Gürbüz ve Şahin, 2016).

Nicel araştırmalar, sayısal verilerin ölçek, test gibi araçlar ile toplanması ve bu verileri istatistiksel olarak analiz edilmesiyle genellenebilir sonuçlar elde etmeyi hedefler (Gürbüz ve Şahin, 2016). Deneysel desenlerin amacı araştırmanın değişkenlerinin birbiri ile ilişkisi varsa, neden sonuç ilişkisini belirlemektir (Büyüköztürk, 2016). Deneysel çalışma olarak bir araştırmanın isimlendirilmesi, deneklerin deney ve kontrol gruplarına seçkisiz olarak atanmasıdır (Hovardalıŏglu, 2000; akt. Büyüköztürk, 2016). Çalışmanın deseni öntest-sontest kontrol gruplu desen olarak seçilmiş̧ir. Denekler deneysel uygulamadan önce ve sonra ölçülmelerinin yanında, deney ve kontrol gruplarının aynı zamanda öntest-sontest karşılaştırmasını gruplar arasında da yapmayı amaçlamaktadır. Aynı kişilerin bağımlı değişken üzerinde iki kere ölçülmeleri yanında, farklı grup üyelerinden oluşan deney-kontrol gruplarına ait ölçümlerin karşılaştırılması sebebiyle, bu desen karış1k bir desen olarak nitelendirilir (Howitt, 1997; akt. Büyüköztürk, 2016).

2017-2018 öğretim y1lında İstanbul ili Küçükçekmece ilçesinde bulunan Milli Eğitim Bakanlığına bağlı resmi okul öncesi kurumları araştırmanın evrenini oluşturmaktadır. Çalışmanın örneklemini ise aynı ilçede bulunan üç bağımsız okul öncesi eğitim kurumlarında eğim gören 40 
kaynaştırma öğrencisi oluşturmaktadır. Bu öğrencilerin 20'si destek eğitim odasında kaynaştırma eğitimi alırken diğer 20'si ise destek eğitim odasında eğitim almadan kaynaştırma eğitimine tabi tutulmuştur. Örnekleme olarak amaca uygun örnekleme yapılmış ancak seçilen gruplar deney ve kontrol grubu olarak seçkisiz olarak atanmıştır.

$\mathrm{Bu}$ araştırmada verileri toplayabilmek için anket uygulaması yapılmıştır (Karasar, 2005). Veriler Milli Eğitim Bakanlığı tarafından hazırlanan Eğitsel Değerlendirme Formu (EDF) yardımıyla elde edilmiştir. Dört bölümden oluşan Eğitsel değerlendirme formunun birinci bölümünde öğrencinin tanınma bilgileri ve eğitsel değerlendirmenin istenme sebebi; ikinci bölümde beceri alanları (Psiko-motor bölüm: 25 madde ile öğrencilerin motor becerileri tespitine yönelik değerlendirme içermektedir. Bilișsel beceri bölümü: 16 madde ile zihinsel beceriler gerektiren anlama yorumlama becerilerini kapsar. Öz bakım becerileri bölümü: Öz bakımı içeren becerileri ölçen 9 madde olarak bulunmaktadır.); üçüncü bölümde gelişim alanları ( Dil gelişim alanı: Öğrendiklerini ve kendisi ile ilgili durumları ifade edebilmesini ölçen 12 madde içermektedir. Sosyal duygusal gelişim: sosyal kuralları ve duygularını açıklayabilmeyi ölçmeyi amaçlayan 10 madde bulunmaktadır.) ve dördüncü bölümde 33 madde ile öğrenci yetersizliklerine ilişkin gözlemler içeren bölümler bulunmaktadır. Eğitsel Değerlendirme Formunda (EDF) bulunan maddelerin, öğrencinin öğretmeni tarafından (varsa okul rehber öğretmeni ile birlikte), velisi ve okul yöneticilerinin öğrenci hakkındaki görüşleri de dikkate alınarak düzenlenmesi gereklidir.

Eğitsel değerlendirme formu ile aşağıda verilen her bir madde ile ilgili olarak;

Öğrencide o davranış veya beceri hiç yoksa (0), Nadiren varsa (yapıyorsa) (1),

Çoğunlukla varsa (yapıyorsa) (2), Tam olarak varsa (yapıyorsa) (3)

Yapılan anket ölçümün matematiksel olarak ifade edilmesi:

$1-2-3 / 4=0,75$

1) $0,00-0,74$ arası değer hiç yapamıyor.

2) $0,75-1,49$ arası değer nadiren yapıyor.

3) 1,50-2,24 arası değer çoğunlukla yapıyor

4) 2,25 - 3,00 arası değer tam yapıyor.

Çalışmanın modelinde deney grubunu "Destek odasında kaynaştırma eğitimi alan okul öncesi öğrencileri” ve kontrol grubunu ise "Sadece kaynaştırma eğitimi alan okul öncesi öğrencileri”" oluşturmaktadır.

Tablo 1: Modelin Simgesel Görünümü

\begin{tabular}{clll}
\hline & ÖN TEST & & SON TEST \\
\hline $\mathrm{G}_{\mathrm{D}}$ & $\mathrm{O}_{1}$ & $\mathrm{X}$ & $\mathrm{O}_{2}$ \\
$\mathrm{G}_{\mathrm{K}}$ & $\mathrm{O}_{3}$ & & $\mathrm{O}_{4}$ \\
\hline
\end{tabular}

Modelden ön testlerin yer alması, gruplar tarafindan sahip olunan deney öncesi benzerlik düzeylerinin görülmesini ve son test verilerinin de bunlara göre düzenlenmesine destek olur.

G1 Deney (Destek Odasında Kaynaştırma Eğitimi Alan-DOKE)

G2 Kontrol (Sadece Kaynaştırma Eğitimi Alan-SaKE) 
Bu modelde "x" değişkeninin etki düzeyi hakkında sonuca ulaşmak için ön test ve son test ölçümleri birlikte kullanılır. Öntest-sontest kontrol gruplu desenler için önerilen veri analizleri olarak t-test; tek faktörlü varyans analizi (ANOVA) kullanılabilmektedir (Büyüköztürk, 2016). Bu analizlerin yapılabilirliğini belirlemek amacıyla verilerin normal dağılıma sahip olma durumunu incelemek amacı ile Kolmogorov-Smirnov testi ve Shapiro-Wilk testi yapılmış ve Tablo 2, 3, 4 ve 5 'de sonuçlar sunulmuştur.

Tablo 2: Öğrencilerin Destek Eğitim Odası Eğitimi Öncesi EDF Puanlarının Normallik Testi Sonuçları

\begin{tabular}{ccccccccc}
\hline \multirow{2}{*}{ Değerler } & $\mathbf{N}$ & \multicolumn{2}{c}{$\begin{array}{c}\text { Normal } \\
\text { Parametreler }\end{array}$} & $\begin{array}{c}\text { Kolmogorov- } \\
\text { Smirnov Z }\end{array}$ & $\mathbf{p}$ & Shapiro-Wilk Z & p \\
\cline { 3 - 6 } & $\overline{\mathrm{x}}$ & ss & &, 131 &, 088 &, 967 &, 302 \\
\hline Ölçek & 40 & 1,52 &, 37 &, 131 & &
\end{tabular}

Tablo 2'de, öğrencilerin destek eğitim odas1 eğitimi öncesi puanları dağılımın normalliğini denetlemek amacı ile yapılan Kolmogorov-Smirnov $(z=, 131 ; p>, 05)$ ve Shapiro-Wilk testi $(z=, 967$; $\mathrm{p}>, 05)$ sonuçları bulunmaktadır. Ölçek puanları dağılımlarının normal dağılımdan önemli bir farklılık göstermediği saptanmıştır.

Tablo 3:Destek Eğitimi Alan Öğrencilerin (DOKE) Ön test-Son test EDF Puanları Normallik Testi Sonuçları

\begin{tabular}{|c|c|c|c|c|c|c|c|}
\hline \multirow[t]{2}{*}{ Değerler } & \multirow[t]{2}{*}{$\mathbf{N}$} & \multicolumn{2}{|c|}{$\begin{array}{c}\text { Normal } \\
\text { Parametreler }\end{array}$} & \multirow{2}{*}{$\begin{array}{r}\text { Kolmogor } \\
\text { ov-Smirnov Z }\end{array}$} & \multirow{2}{*}{$\mathbf{p}$} & \multirow{2}{*}{$\begin{array}{c}\text { Shapiro-Wilk } \\
\text { Z }\end{array}$} & \multirow{2}{*}{$\mathbf{p}$} \\
\hline & & $\overline{\mathrm{X}}$ & $S S$ & & & & \\
\hline Ölçek & 40 & 1,82 & ,48 &, 073 & ,200 & ,980 & 686, \\
\hline
\end{tabular}

Tablo 3’te görüldüğü üzere, okul öncesi öğrencilerinin destek eğitim odasında kaynaştırma eğitimi alan ve almayanların ön test-son test ortalamaları için Kolmogorov-Smirnov $(z=, 073 ; p>, 05)$ ve Shapiro-Wilk $(\mathrm{z}=, 980 ; \mathrm{p}>, 05)$ testi yapılmıştır. Test sonucunda elde edilen değerler sonucunda dağılımlarının normal dağılımdan önemli bir farklılık göstermediği saptanmış ve dağılım normal kabul edilmiştir.

Tablo 4: Sadece Kaynaştırma Eğitimi Alan Öğrencilerin (SaKE) Ön test-Son test EDF Puanlarının Normallik Testi Sonuçları

\begin{tabular}{|c|c|c|c|c|c|c|c|}
\hline \multirow{2}{*}{ Değerler } & \multirow[t]{2}{*}{$\mathbf{N}$} & \multicolumn{2}{|c|}{$\begin{array}{c}\text { Normal } \\
\text { Parametreler }\end{array}$} & \multirow{2}{*}{$\begin{array}{r}\text { Kolmogor } \\
\text { ov-Smirnov Z }\end{array}$} & \multirow{2}{*}{ p } & \multirow{2}{*}{$\begin{array}{l}\text { Shapiro-Wilk } \\
\text { Z }\end{array}$} & \multirow{2}{*}{$\mathbf{p}$} \\
\hline & & $\overline{\mathrm{x}}$ & ss & & & & \\
\hline Ölçek & 40 & 1,60 & ,33 & ,084 & ,200 & 973 & ,480 \\
\hline
\end{tabular}

Tablo 4'te oluşan sonuçlarda görüldüğü üzere, okul öncesi kaynaştırma öğrencilerinin ön test-son test ortalamaları dağılımlarının normal dağılımdan önemli bir farklılık göstermediği, 
Kolmogorov-Smirnov testi $(\mathrm{z}=, 084 ; \mathrm{p}>, 05)$ ve Shapiro-Wilk testi $(\mathrm{z}=, 973 ; \mathrm{p}>, 05)$, saptanmış ve dağılım normal kabul edilmiştir.

Tablo 5: Öğrencilerin Destek Eğitim Odası Eğitimi Sonrası EDF Puanlarının Normallik Testi Sonuçları

\begin{tabular}{cccccccc}
\hline \multirow{2}{*}{ Değerler } & $\mathbf{N}$ & \multicolumn{2}{c}{$\begin{array}{c}\text { Normal } \\
\text { Parametreler }\end{array}$} & \multirow{2}{*}{$\begin{array}{c}\text { Kolmogorov } \\
-\end{array}$} & $\mathbf{p}$ & $\begin{array}{c}\text { Shapiro-Wilk } \\
\mathbf{Z}\end{array}$ & $\mathbf{p}$ \\
\cline { 2 - 4 } & & $\overline{\mathrm{x}}$ & $s S$ & Smirnov Z & & & \\
\hline Ölçek & 40 & 1,90 &, 39 &, 069 &, 200 &, 979 &, 667 \\
\hline
\end{tabular}

Tablo 5' de görüldüğü üzere, öğrencilerin destek eğitim odas1 eğitimi sonras1 puanlar1 dağılımın normalliğini denetlemek amacı ile yapılan Kolmogorov-Smirnov testi $(z=, 069 ; p>, 05)$ ve Shapiro-Wilk testi $(\mathrm{z}=, 979 ; \mathrm{p}>, 05)$ sonucunda ölçek puanları dağılımlarının normal dağılımdan önemli bir farklılık göstermediği saptanmış ve dağılım normal kabul edilmiştir.

\section{Bulgular} almaktadır.

Verilerin istatistiksel analizi sonucunda elde edilen bulgular ve yorumları bu bölümde yer

\section{Grupların Çalışma Başlangıcındaki Durumlarına İlişkin Bulgular ve Yorum}

Araştırmanın başlangıcında her iki grup için "Okul öncesi eğitiminde destek odasında kaynaştırma eğitimi (DOKE) alan öğrenciler ile sadece kaynaştırma eğitimi alan (SaKE) öğrencilerin eğitim öncesi Eğitsel Değerlendirme Formu (EDF) puanları arasında anlamlı bir fark var midır?" sorusuna yanıt aranmıştır. Deney (DOKE) ve kontrol (SaKE) gruplarının Eğitim Değerlendirme Formu (EDF) puanlarının çalışmanın başında farklı olup olmadığını belirlemek amacıyla yapılan t-testi sonuçları Tablo 6'da sunulmuştur.

Tablo 6: Öğrencilerin Destek Eğitim Odası Eğitimi Öncesi EDF Puanlarının Deney (DOKE) ve Kontrol (SaKE) Gruplarına Göre Bağımsız Grup t-testi Sonuçları

\begin{tabular}{|c|c|c|c|c|c|c|c|c|}
\hline \multirow{2}{*}{ Boyutlar } & \multirow{2}{*}{ Gruplar } & \multirow{2}{*}{$N$} & \multirow{2}{*}{$\overline{\mathrm{x}}$} & \multirow{2}{*}{ SS } & \multirow{2}{*}{$\mathrm{Sh}_{\overline{\mathrm{x}}}$} & \multicolumn{3}{|c|}{$t$ Testi } \\
\hline & & & & & & $t$ & $S d$ & $p$ \\
\hline \multirow{2}{*}{ Psikomotor Beceriler } & DOKE & 20 & 1,52 &, 54 &, 12 & \multirow{2}{*}{,- 468} & \multirow{2}{*}{37} & \multirow{2}{*}{,642 } \\
\hline & SaKE & 20 & 1,62 & ,79 &, 18 & & & \\
\hline \multirow{2}{*}{ Bilişsel Beceriler } & DOKE & 20 & 1,27 &, 70 & 16 & \multirow{2}{*}{,- 228} & \multirow{2}{*}{37} & \multirow{2}{*}{,821 } \\
\hline & SaKE & 20 & 1,32 & ,68 & ,16 & & & \\
\hline \multirow{2}{*}{ Dil Gelişimi } & DOKE & 20 & 1,21 & ,73 & ,16 & \multirow{2}{*}{,- 198} & \multirow{2}{*}{38} & \multirow{2}{*}{,844 } \\
\hline & SaKE & 20 & 1,25 &, 43 &, 10 & & & \\
\hline \multirow{2}{*}{ Öz Bakım Becerileri } & DOKE & 20 & 1,68 & ,64 &, 14 & \multirow{2}{*}{,221 } & \multirow{2}{*}{37} & \multirow{2}{*}{,827 } \\
\hline & SaKE & 20 & 1,63 & ,66 &, 15 & & & \\
\hline \multirow{2}{*}{$\begin{array}{c}\text { Sosyal ve Duygusal } \\
\text { Gelişim }\end{array}$} & DOKE & 20 & 1,42 & ,64 & ,14 & \multirow{2}{*}{,- 004} & \multirow{2}{*}{37} & \multirow{2}{*}{,996 } \\
\hline & SaKE & 20 & 1,42 &, 45 &, 10 & & & \\
\hline \multirow{2}{*}{$\begin{array}{l}\text { Öğrencinin } \\
\text { Yetersizliklerine İlişkin } \\
\text { Gözlemler }\end{array}$} & DOKE & 20 & 1,74 &, 37 & 08 & \multirow{2}{*}{, 478 } & \multirow{2}{*}{37} & \multirow{2}{*}{636} \\
\hline & SaKE & 20 & 1,69 &, 33 &, 08 & & & \\
\hline
\end{tabular}


Tablo 6'da görüldüğü üzere bağımsız grup t-testi sonucunda; destek eğitim odalarındaki eğitim başlamadan önce kaynaştırma eğitimi alacak ve destek eğitimi alacak öğrencilerin Eğitsel Değerlendirme Formu (EDF) alt boyut puanları arasında anlamlı fark bulunmamaktadır. Psikomotor beceriler boyutu puanları [ $\mathrm{t}(37)=-, 468 ; \mathrm{p}>, 05]$, bilişsel beceriler boyutu puanları $\left[\mathrm{t}\left({ }_{37}\right)=-, 228 ; \mathrm{p}>, 05\right]$, dil gelişimi boyutu puanları [ $\mathrm{t}(38)=-, 198 ; \mathrm{p}>, 05]$, öz bakım becerileri boyutu puanları $[\mathrm{t}(37)=, 221$; $\mathrm{p}>, 05]$, sosyal ve duygusal gelişim boyutu puanları [t(37)=-,004; $\mathrm{p}>, 05]$, öğrenciye yetersizliklerine göre ilişkin gözlemler boyutu puanları [ $\mathrm{t}(37)=, 478 ; \mathrm{p}>, 05] \mathrm{t}$-testi sonuçları anlamlı fark olmadığını göstermektedir. Deney ve kontrol gruplarına atanmış olan öğrenciler arasında anlamlı fark bulunmaması nedeniyle öğrencilerin Eğitsel Değerlendirme Formu (EDF) ile ölçülen özellikleri arasında başlangıçta birbirine benzer olduğu söylenebilmektedir.

\section{Araştırmanın Birinci Alt Problemine İlişkin Bulgular ve Yorum}

Araştırmada birinci alt problemi olarak yer alan "Okul öncesi eğitiminde destek odasında kaynaştırma eğitimi (DOKE) alan öğrencilerin Eğitsel Değerlendirme Formu (EDF) öntest -sontest puanları karşılaştırtıldığında aralarında anlamlı fark bulunmakta mıdır?" sorusuna cevap aranmıştır.

Tablo 7: Destek Eğitimi Alan Öğrencilerin (DOKE) Ön test-Son test EDF Puanları İlişkili Grup ttesti Sonuçları

\begin{tabular}{|c|c|c|c|c|c|c|c|c|}
\hline \multirow{2}{*}{ Puan } & \multirow{2}{*}{ Ölçüm } & \multirow{2}{*}{$N$} & \multirow{2}{*}{$\overline{\mathrm{x}}$} & \multirow{2}{*}{ ss } & \multirow{2}{*}{$\mathrm{Sh}_{\overline{\mathrm{x}}}$} & \multicolumn{3}{|c|}{$t$ testi } \\
\hline & & & & & & $t$ & $S d$ & $p$ \\
\hline \multirow{2}{*}{$\begin{array}{l}\text { Psikomotor } \\
\text { Beceriler }\end{array}$} & Ön test & 20 & 1,52 &, 54 & ,12 & \multirow{2}{*}{$-8,447$} & \multirow{2}{*}{19} & \multirow{2}{*}{, 000} \\
\hline & Son test & 20 & 2,34 &, 44 &, 10 & & & \\
\hline \multirow{2}{*}{ Bilişsel Beceriler } & Ön test & 20 & 1,27 &, 70 & , 16 & \multirow{2}{*}{$-7,540$} & \multirow{2}{*}{19} & \multirow{2}{*}{,000 } \\
\hline & Son test & 20 & 2,19 &, 53 &, 12 & & & \\
\hline \multirow{2}{*}{ Dil Gelişismi } & Ön test & 20 & 1,21 &, 73 & ,16 & \multirow{2}{*}{$-6,269$} & \multirow{2}{*}{19} & \multirow{2}{*}{,000 } \\
\hline & Son test & 20 & 1,98 & ,46 &, 10 & & & \\
\hline \multirow{2}{*}{ Öz Bakım Becerileri } & Ön test & 20 & 1,68 & ,64 &, 14 & \multirow{2}{*}{$-4,923$} & \multirow{2}{*}{19} & \multirow{2}{*}{000} \\
\hline & Son test & 20 & 2,38 &, 57 &, 13 & & & \\
\hline \multirow{2}{*}{$\begin{array}{c}\text { Sosyal ve Duygusal } \\
\text { Gelişim }\end{array}$} & Ön test & 20 & 1,42 & ,64 &, 14 & \multirow[t]{2}{*}{$-4,414$} & \multirow[t]{2}{*}{19} & \multirow[t]{2}{*}{,000 } \\
\hline & Son test & 20 & 2,05 &, 48 &, 11 & & & \\
\hline \multirow{2}{*}{$\begin{array}{c}\text { Öğrencinin } \\
\text { Yetersizliklerine } \\
\text { İlișkin Gözlemler }\end{array}$} & Ön test & 20 & 1,74 &, 37 & ,08 & \multirow[t]{2}{*}{$-1,744$} & \multirow[t]{2}{*}{19} & \multirow[t]{2}{*}{,097 } \\
\hline & Son test & 20 & 1,94 &, 55 & ,12 & & & \\
\hline
\end{tabular}

Tablo 7'de görüldügü üzere, okul öncesi öğrencilerinin destek eğitim odasında kaynaştırma eğitimi alanların eğitimi ön test-son test ortalamaları arasında anlamlı bir fark bulunup bulunmadığını belirlemek amacıyla ilişkili gruplar $\mathrm{t}$-testi sonucuna bakılmıştır. Psikomotor beceriler boyutu $\left[\mathrm{t}\left({ }_{20}\right)=\right.$ $-8,477 ; \mathrm{p}<, 05]$, bilişsel beceriler alt boyutu [ $\mathrm{t}(20)=-7,540 ; \mathrm{p}<, 05]$, dil gelişimi boyutu $[\mathrm{t}(20)=-6,269$; $\mathrm{p}<, 05]$, öz bakım becerileri alt boyutu [t $(20)=-4,923 ; \mathrm{p}<, 05]$, sosyal ve duygusal gelişim boyutu $[\mathrm{t}(20)=-4,414 ; \mathrm{p}<, 05]$ puanları arasında son test lehine anlamlı fark bulunmuştur. Destek odasinda verilen eğitimin, okul öncesinde destek odasında eğitim alan öğrencilerin psikomotor becerilerinin, bilişsel becerilerinin, dil gelişiminin, öz bakım becerilerinin, sosyal ve duygusal gelişiminin ilerlemesinde önemli derecede etkili olduğu söylenebilir. Buna karşın öğrenciye yetersizliklerine 
ilişkin gözlemler boyutu $[\mathrm{t}(20)=-1,477 ; \mathrm{p}<, 05]$ puanları arasında gruplar arası fark anlamlı bulunmamıştır.

\section{Araştırmanın İkinci Alt Problemine İlişkin Bulgular ve Yorum}

Araştırmanın ikinci alt problemi olan “ Okul öncesi eğitiminde sadece kaynaştırma eğitimi alan (SaKE) öğrencilerin öntest sontest puanları karşılaştırtıldığında aralarında anlamlı fark bulunmakta mıdır?" sorusuna yanıt aranmıştır.

Tablo 8: Sadece Kaynaştırma Eğitimi Alan Öğrencilerin (SaKE) Ön test-Son test EDF Puanları İlişkili Grup t-testi Sonuçları

\begin{tabular}{|c|c|c|c|c|c|c|c|c|}
\hline \multirow{2}{*}{ Puan } & \multirow{2}{*}{ Ölçüm } & \multirow{2}{*}{$N$} & \multirow{2}{*}{$\overline{\mathrm{x}}$} & \multirow{2}{*}{ sS } & \multirow{2}{*}{$\mathrm{Sh}_{\overline{\mathrm{x}}}$} & \multicolumn{3}{|c|}{$t$ testi } \\
\hline & & & & & & $t$ & $S d$ & $p$ \\
\hline \multirow[t]{2}{*}{ Psikomotor Beceriler } & Ön test & 20 & 1,62 & ,79 &, 18 & \multirow[t]{2}{*}{,- 719} & \multirow[t]{2}{*}{18} & \multirow[t]{2}{*}{,481 } \\
\hline & Son test & 20 & 1,71 &, 53 &, 12 & & & \\
\hline \multirow[t]{2}{*}{ Bilişsel Beceriler } & Ön test & 20 & 1,32 & ,68 &, 16 & \multirow[t]{2}{*}{$-2,895$} & \multirow[t]{2}{*}{18} & \multirow[t]{2}{*}{, 010} \\
\hline & Son test & 20 & 1,68 &, 52 &, 12 & & & \\
\hline \multirow[t]{2}{*}{ Dil Gelişimi } & Ön test & 20 & 1,25 & ,43 &, 10 & \multirow[t]{2}{*}{$-4,170$} & \multirow[t]{2}{*}{19} & \multirow[t]{2}{*}{, 001} \\
\hline & Son test & 20 & 1,70 &, 51 &, 11 & & & \\
\hline \multirow[t]{2}{*}{ Öz Bakım Becerileri } & Ön test & 20 & 1,63 & ,66 &, 15 & \multirow[t]{2}{*}{,- 622} & \multirow[t]{2}{*}{18} & \multirow[t]{2}{*}{,542 } \\
\hline & Son test & 20 & 1,73 &, 67 &, 15 & & & \\
\hline \multirow{2}{*}{$\begin{array}{c}\text { Sosyal ve Duygusal } \\
\text { Gelişim }\end{array}$} & Ön test & 20 & 1,42 & , 45 &, 10 & \multirow{2}{*}{$-2,182$} & \multirow[t]{2}{*}{18} & \multirow[t]{2}{*}{,043 } \\
\hline & Son test & 20 & 1,73 & , 49 & ,11 & & & \\
\hline \multirow{2}{*}{$\begin{array}{c}\text { Öğrencinin } \\
\text { Yetersizliklerine } \\
\text { İlişkin Gözlemler }\end{array}$} & Ön test & 20 & 1,69 & ,33 &, 08 & \multirow[t]{2}{*}{1,503} & \multirow[t]{2}{*}{18} & \multirow[t]{2}{*}{, 150} \\
\hline & Son test & 20 & 1,56 & ,24 &, 05 & & & \\
\hline
\end{tabular}

Tablo 8'de görüldüğü üzere, okul öncesi sadece kaynaştırma eğitimi alan öğrencilerinin ön test-son test ortalamaları arasında anlamlı bir fark bulunup bulunmadığını belirlemek amaciyla ilişkili gruplar t-testi yapılmıştır. Analiz sonucunda bilişsel beceriler alt boyutu [ $\left.\mathrm{t}\left({ }_{20}\right)=-2,895 ; \mathrm{p}<, 05\right]$, dil gelişimi boyutu $[\mathrm{t}(20)=-4,170 ; \mathrm{p}<, 05]$, sosyal ve duygusal gelişim boyutu $[\mathrm{t}(20)=-2,182 ; \mathrm{p}<, 05]$ puanları arasında son test lehine anlamlı fark bulunmuştur. Okul öncesi kaynaştırma eğitimi alan öğrencilerin bilişsel becerilerinin, dil gelişiminin, sosyal ve duygusal gelişiminin ilerlemesinde önemli derecede etkili olduğu söylenebilir. Buna karşın psikomotor beceriler boyutu $[\mathrm{t}(20)=-, 719$; $\mathrm{p}>, 05]$, öz bakım becerileri alt boyutu [t $(20)=-, 622 ; \mathrm{p}>, 05]$ ve öğrenciye yetersizliklerine ilişkin gözlemler boyutu $[\mathrm{t}(20)=1,503 ; \mathrm{p}>, 05]$ puanları arasında gruplar arası fark anlamlı bulunmamıştır. Kaynaştırma eğitimi bazı alt boyutlarda gelişimi desteklemesine rağmen bazı alt boyutlardaki gelişimi yeterince destekleyememektedir.

\section{Araştırmanın Üçüncü Alt Problemine İlişkin Bulgular ve Yorum}

Çalışmadaki üçüncü alt problem "Okul öncesi eğitiminde destek odasında kaynaştırma eğitimi (DOKE) alan öğrenciler ile sadece kaynaştırma eğitimi alan (SaKE) öğrencilerin Eğitsel Değerlendirme Formu (EDF) sontest puanları karşılaştırtıldığında aralarında anlamlı fark bulunmakta mıdır?" için cevap aranmıştır. 
Tablo 9: Öğrencilerin Destek Eğitim Odası Eğitimi Sonrası EDF Puanlarının Deney (DOKE) ve Kontrol (SaKE)Gruplarına Göre Bağımsız Grup t-testi Sonuçları

\begin{tabular}{|c|c|c|c|c|c|c|c|c|}
\hline \multirow{2}{*}{ Boyutlar } & \multirow{2}{*}{ Gruplar } & \multirow{2}{*}{$N$} & \multirow{2}{*}{$\overline{\mathrm{X}}$} & \multirow{2}{*}{$s S$} & \multirow{2}{*}{$\mathrm{Sh}_{\overline{\mathrm{x}}}$} & \multicolumn{3}{|c|}{$t$ testi } \\
\hline & & & & & & $t$ & $S d$ & $p$ \\
\hline \multirow{2}{*}{ Psikomotor Beceriler } & DOKE & 20 & 2,34 & ,44 &, 10 & \multirow{2}{*}{3,998} & \multirow{2}{*}{37} & \multirow{2}{*}{, 000 } \\
\hline & SaKE & 20 & 1,71 & ,53 & , 12 & & & \\
\hline \multirow{2}{*}{ Bilişsel Beceriler } & DOKE & 20 & 2,19 &, 53 &, 12 & \multirow{2}{*}{2,998} & \multirow{2}{*}{37} & \multirow{2}{*}{,005 } \\
\hline & $\mathrm{SaKE}$ & 20 & 1,68 &, 52 &, 12 & & & \\
\hline \multirow{2}{*}{ Dil Gelişimi } & DOKE & 20 & 1,98 & ,46 &, 10 & \multirow{2}{*}{1,833} & \multirow{2}{*}{38} & \multirow{2}{*}{,075 } \\
\hline & $\mathrm{SaKE}$ & 20 & 1,70 &, 51 &, 11 & & & \\
\hline \multirow{2}{*}{ Öz Bakım Becerileri } & DOKE & 20 & 2,38 &, 57 & 13 & \multirow{2}{*}{3,246} & \multirow{2}{*}{37} & \multirow{2}{*}{,002 } \\
\hline & $\mathrm{SaKE}$ & 20 & 1,73 &, 67 &, 15 & & & \\
\hline \multirow{2}{*}{$\begin{array}{l}\text { Sosyal ve Duygusal } \\
\text { Gelişim }\end{array}$} & DOKE & 20 & 2,04 & , 48 &, 11 & \multirow{2}{*}{2,016} & \multirow{2}{*}{37} & \multirow{2}{*}{, 051} \\
\hline & SaKE & 20 & 1,73 & ,49 &, 11 & & & \\
\hline \multirow{2}{*}{$\begin{array}{c}\text { Öğrencinin } \\
\text { Yetersizliklerine İlişkin } \\
\text { Gözlemler }\end{array}$} & DOKE & 20 & 1,94 &, 55 &, 12 & \multirow{2}{*}{2,774} & \multirow{2}{*}{37} & \multirow{2}{*}{,009 } \\
\hline & SaKE & 20 & 1,56 & ,24 & 05 & & & \\
\hline
\end{tabular}

Tablo 9'da görüldüğü üzere bağımsız grup t-testi yapılan DOKE ve SaKE grupları arasında alt boyutların çoğunda anlamlı farklılıklar bulunmuştur. Destek eğitim odasında destek eğitimi alan öğrencilerine verilen eğitim, kaynaştırma öğrencilerinin aldığı eğitime göre öğrencilerin psikomotor, bilişsel ve öz bakım becerilerinin gelişmesinde ve öğrenciye yetersizliklerine ilişkin gözlemlere olumlu biçimde yansımasına daha fazla olanak sağlamaktadır. Buna karşın dil gelişimi boyutu puanlarının [ $\mathrm{t}(38)=1,833 ; \mathrm{p}>, 05]$, sosyal ve duygusal gelişim boyutu puanlarının [ $\mathrm{t}(37)=2,061 ; \mathrm{p}>, 05]$, destek eğitim ve kaynaştırma grupları karşılaştırıldığında aralarında anlamlı fark görülmemektedir. Sadece kaynaştırma eğitimi verilmesinin yanında bu eğitimin destek odalarındaki eğitim ile de desteklenmesi öğrenciler açısından daha etkin sonuçlar üretmektedir.

\section{Sonuç ve Tartışma}

$\mathrm{Bu}$ çalışmanın bulguları 1şı̆̆ında; destek eğitimi alan 0-6 yaş arası kaynaştırma öğrencilerinin gösterdikleri gelişime bakıldığında aşağıda belirtilen sonuçlar bulunmuştur.

Erken çocukluk olarak isimlendirilen 0-6 yaş arası çocuklara eğitim veren kurumlarda destek eğitim odasında söz konusu eğitimi alan 0-6 yaş arası kaynaştırma öğrencileri ile bu eğitimi alamayan; yalnızca kaynaştırma eğitimi alan 0-6 yaş arası kaynaştırma öğrencilerinin gelişimlerini kıyaslamak amacı ile bu çalışma gerçekleştirilmiştir. Kaynaştırma öğrencilerinin destek eğitim odasında almış oldukları eğitim sonucu ortaya çıkan gelişim düzeyi belirlenmiştir. 0-6 yaş arası çocuklara eğitim veren kurumlarda kaynaştırma öğrencilerinin ve destek eğitimi alan öğrencilerin gelişim seviyeleri tespit edilmiştir. Eğitim sonunda destek eğitimi alan öğrenciler ile bu eğitimi almayan; yalnızca kaynaştırma eğitimi alan 0-6 yaş arası öğrencilerin gelişim seviyeleri belirlenmiştir.

Destek eğitimi alan kaynaştırma öğrencilerinin söz konusu eğitim öncesi tatbik edilen eğitsel değerlendirme formunda psikomotor becerileri ortalamas $\overline{\mathrm{x}}=1,52$; sadece kaynaştırma eğitimi alan öğrencilerin ortalaması ise $\bar{x}=1,62$ olarak ölçülmüştür. Eğitim öncesinde elde edilen sonuçlara göre öğrencilerin psikomotor becerileri arasındaki farklılığın anlamlı olmadığı tespit edilmiştir. Bilişsel beceri alanlarında sadece kaynaştırma eğitim alan öğrencilerin beceri düzeyleri ortalaması $\bar{x}=1,32$ iken destek eğitimi alan çocukların eğitime başlamadan önceki bilişsel beceri ortalamasının $\bar{x}=1,27$ 
olduğu belirlenmiştir. $\mathrm{Bu}$ eğitimi almadan önceki bilişsel beceri düzeylerinin yeterli olmadığ1 anlaşılmıştır. Kaynaştırma öğrencilerinin dil gelişiminin eğitimden önceki seviyesi $\bar{x}=1,25$ iken destek eğitim odasındaki öğrencilerin $\overline{\mathrm{x}}=1,21$ olduğu belirlenmiştir. Bu iki grup incelendiğinde dil gelişimi seviyesinin yeterli olmadığı görülmüştür. Öz bakım beceri düzeyleri eğitim öncesi kaynaştırma öğrencilerin için $\bar{x}=1,63$ iken destek eğitim odası öğrencileri için eğitim öncesi beceri düzeyleri $\bar{x}=1,68$ şeklinde görülmüştür. Öz bakım becerilerinin eğitimden önce; iki grupta da yeterli olmadığı belirlenmiştir. Öğrencilerin sosyal beceri ve duygusal gelişim alanları eğitim öncesi gelişim düzeyleri $\bar{x}=1,42$ iken destek eğitim odası öğrencilerinin de $\bar{x}=1,42$ olduğu belirlenmiştir. Söz konusu eğitimden önce iki grubun öğrencilerinin gelişim seviyelerinin yeterli olmadığ belirlenmiştir. Yapılan gözlemler neticesinde; eğitim öncesi yeterli düzeyde olmayan kaynaştırma öğrencilerinin $\bar{x}=1,69$ iken destek eğitim odası öğrencilerinin eğitim öncesi seviyeleri $\bar{x}=1,74$ olarak belirlenmiştir.

Eğitsel değerlendirme formunun tüm alt boyutları baz alındığında destek eğitimi alan ve almayan kaynaştırma öğrencilerinin puanları arasında farklılık gözlenmemiştir. Kaynaştırma öğrencilerinin destek eğitimi almadan önceki psikomotor beceri düzeyi $\bar{x}=1,52$ iken eğitim sonras1 beceri düzeyinin $\bar{x}=2,34$ olduğu görülmüsstür. Destek eğitimi sonrası öğrencilerin psikomotor becerilerinde anlamlı düzeyde ilerleme olduğu saptanmıştır. Eğitimler öncesi bilişsel beceri düzeyi $\overline{\mathrm{x}}=1,27$ olarak gözlemlenirken, eğitim sonrası söz konusu düzeyin $\overline{\mathrm{x}}=2,19$ olduğu gözlemlenmiştir. Destek eğitimi sonucuna bakıldığında öğrencilerin beceri seviyelerinde önemli bir ilerleme olduğu tespit edilmiştir. Dil gelişim seviyesi eğitimden önce $\bar{x}=1,21$ iken eğitim sonras1 $\bar{x}=1,98$ olduğu görülmüş ve eğitim sonrası dil gelişiminde ilerleme olduğu anlaşılmıştır. Eğitim öncesi öz bakım beceri seviyeleri $\bar{x}=1,68$ iken eğitim sonrası $\bar{x}=2,38$ olduğu belirlenmiştir. Öz bakım becerilerinde eğitim sonrası önemli bir gelişme olduğu tespit edilmiştir. Eğitimden önce öğrencilerin sosyal becerileri ve duygusal gelişim alanındaki ortalamaları $\overline{\mathrm{x}}=1,42$ iken eğitim sonras $\overline{\mathrm{x}}=2,05$ olduğu belirlenmiştir. Öğrencilerde hem sosyal hem de duygusal gelişimlerinde ilerleme olduğu gözlemlenmiş̧tir. Bunula birlikte destek eğitimi almayan öğrencilerin psikomotor becerisi eğitim öncesi $\bar{x}=1,62$ iken eğitim sonrası $\bar{x}=1,71$ olarak ortaya çıkmıştır. Psikomotor becerilerinde alınan eğitim sonucu belirli bir farkl1lık görülmemiştir. Eğitim öncesi bilişsel beceri düzeyi $\bar{x}=1,32$ iken eğitim sonrası $\bar{x}=1,68$ olduğu görülmüştür. Eğitim sonrası ilerlemenin anlamlı düzeyde olduğu gözlemlenmiştir. Eğitim öncesi dil gelişim becerileri $\bar{x}=1,25$ iken eğitim sonrası $\bar{x}=1,70$ olduğu tespit edilmiştir. Eğitim sonrası anlamlı düzeyde önemli bir ilerleme olduğu gözlemlenmiş̧ir. Öz bakım becerilerinde eğitimden önceki düzey $\bar{x}=1,63$ iken eğitim sonras1 $\bar{x}=1,73$ olduğu görülmüştür. Öz bakım becerilerinde eğitim sonrasına kıyasla müspet bir gelişme olmadığ 1 görülmüştür. Eğitim öncesi sosyal ve duygusal gelişim becerileri $\bar{x}=1,42$ iken eğitim sonrasında $\bar{x}=1,73$ olduğu tespit edilmiştir. Sonuç olarak eğitim sonunda; duygusal ve sosyal gelişim alanlarında anlamlı düzeyde önemli bir ilerleme olduğu gözlemlenmiştir. Eğitim öncesi öğrencinin yeterli olmadığına dair düzeyi $\overline{\mathrm{x}}=1,69$ iken eğitin sonunda $\overline{\mathrm{x}}=1,58$ olarak tespit edilmiştir. Eğitim sonunda öğrencilerde gözlemlenen yetersizlik seviyelerinde pozitif bir gelişme olmadığı görülmüştür. Destek eğitimi almayan; sadece kaynaştırma eğitimi alan 0-6 yaş öğrencisinin bilişsel beceri, dil gelişimi, sosyal ve duygusal gelişimi alt boyutlarında anlamlı bir fark olduğu, diğer alt boyutlarda ise önemli bir farklılık olmadığı tespit edilmiştir. Buna istinaden 0-6 yaş kaynaştırma öğrencilerine verilen eğitimin bilişsel beceri, sosyal, duygusal ve dil gelişimi alanlarında başarılı olduğu, fakat psikomotor beceri ve kişisel bakım yetenekleri alanlarında başarı gösteremediği ifade edilebilir.

Destek eğitimi alan öğrencilerin eğitim sonrası psikomotor becerilerinde motor gelişim düzeyi $\bar{x}=2,34$ iken kaynaştırma eğitimi alanlar için $\bar{x}=1,71$ olarak gözlemlenmiştir. Destek eğitimi alan öğrencilerin psikomotor becerilerinde eğitim sonrası olumlu bir farklılık olduğu belirlenmiştir. Eğitimler sonrası destek eğitimi alan öğrencilerin bilişsel beceri düzeyi $\bar{x}=2,19$ ve yalnızca kaynaştırma eğitimi alan öğrencinin düzeyi ise $\bar{x}=1,68$ olarak belirlenmiştir. Destek eğitimi almış öğrenciler lehine, eğitim sonunda bilişsel becerilerde olumlu bir farklılık olduğu gözlemlenmiştir. 
Destek eğitim odasında eğitim alan öğrencilerin dil gelişimi becerilerinde beceri düzeyi $\bar{x}=1,98$ iken yalnızca kaynaştırma eğitimi alan öğrencilerin dil becerileri $\bar{x}=1,70$ olarak belirlenmiştir. Her iki grup arasında eğitim sonrası önemli bir farklılık bulunmamıştır. Destek eğitim odasında eğitim alan öğrencilerin öz bakım beceri düzeyi $\bar{x}=2,38$ iken sadece kaynaştırma eğitimine katılmış öğrencilerin beceri düzeyi $\bar{x}=1,73$ olarak belirlenmiştir. Öz bakım becerilerinde eğitim sonrası destek eğitim odasında eğitim almış öğrenciler lehine olumlu yönde bir farklılık olduğu görülmüştür. Sosyalleşme bakımından kaynaştırma ortamların öğrencilerin sosyal gelişimine katkı sağladığı farklı çalışmalarda ortaya çıkmıştır (Guralnick \& Bruder, 2016). Ancak destek eğitimi alan öğrencilerin sosyal ve duygusal beceri düzeyi $\bar{x}=2,04$ iken, kaynaştırma eğitimi alan öğrencilerin beceri düzeyi $\bar{x}=1,73$ olarak tespit edilmiştir. Gruplar arasında bir farklılık tespit edilmemiştir.

Sosyal, duygusal ve dil gelişimi alt boyutlarında destek eğitimi alan ve almayan 0-6 yaş kaynaştırma öğrencileri arasında önemli bir farklılık olmasa da her iki alt boyutta destek eğitimi alan öğrencilerin puan ortalamalarının yüksek olduğu ve buna bağlı olarak da bu eğitimin başarıya ulaştığı düşünülebilir.

Buna benzer kaynaştırma öğrencilerine, destek odasında verilen matematik eğitiminin genele göre matematik başarılarının önemli ölçüde arttığı tespit edilmiş, öğretmenler ise kaynaştırma öğrencilerinin öz yeterliliklerinin destek odasındaki eğitime oranla az da olsa arttığını ifade etmişlerdir Ünay (2012). Farklı kaynaştırma eğitimi yaklaşımları ve uygulamalarının, özel gruplar ile yapılan eğitimler gibi, kaynaştırma eğitimine engel olabileceği belirlenmiş olmasına rağmen ( $\mathrm{Hu}$, Mak, Zhang, Fan \& Zhu, 2018), Kutluca Canbulat (2010) destek eğitiminin; psikomotor gelişimi, sosyal ve duygusal beceriler, dil gelişimi ve bilişsel gelişim açısından önemli derecede başarılı olduğu sonucuna varmıştır. Ünal (2008) Türkçe ve Matematik derslerinde de destek eğitimi sonrası beklenen sonuca ulaşıldığı belirlenmiştir. Tunalı Erkan (2018),Öğretmenlerin büyük bir kısmının kaynaştırma öğrencilerine yönelik öğretim içeriğinde belirgin bir düzenleme yapmadığı; yapanların ise; yardıma dayalı çalışma, basit etkinlikler, öğrencilere yönelik etkinlik hazırlama ve içerik tespit çalışmalarına yoğunlaştıkları, diğer çalışmaları ise az sayıda yaptıkları sonucuna ulaşılmış olduğu için bu sonuçların ortaya çıktığı düşünülebilir. Bu sonuçlardan farklı olarak, Kış (2013) yaptığı çalışmasında destek eğitim odası uygulamalarının başarısız olduğu sonucuna ulaşmıştır. Sonuçların farklı olmasında altı yıllık bir sürenin geçmiş olması ve bu süre zarfinda destek odası uygulamalarının gelişmesi söz konusu olabilir.

$\mathrm{Bu}$ çalışmada elde edilen bulgular değerlendirildiğinde farklı öğretmen yaklaşımlarının da ortaya çıkan sonuçlarda etkili olması mümkündür. Yaptıkları çalışmada öğretmenlerin kaynaştırma uygulamalarından sorumlu olup olmadıkları hakkındaki inançları, kaynaştırma eğitimini destekleme düzeylerini belirlemede etkili olmaktadır (Aydın, 2015; Sukumaran, Loveridge \& Green, 2015). Gelecekte yapılacak çalışmalarda nicel deneysel çalışmaların, öğretmen ve veli görüşlerinin de çalışmanın içine katıldığı karma yöntem deseni benimseyerek daha açıklayıcı sonuçlara ulaşılabilir. Öğrencilerin cinsiyet, aile eğitim düzeyleri, ailelerin sosyo-ekonomik durumları gibi değişkenlere göre destek odaları ve kaynaştırma eğitimi ile ilgili nicel, nitel veya karam desen araştırmalar gerçekleştirilebilir.

\section{Kaynakça}

Aydın, A. (2015). Zihinsel yetersizliğe sahip öğrencilere destek ĕgitim odasında verilen eğitim hizmetlerine iliş̧kin öğretmen görüşleri (Yayımlanmamış yüksek lisans tezi). Abant İzzet Baysal Üniversitesi, Bolu.

Batu, S. \& Kırcaali İftar, G. (2006). Kaynaştırma. Ankara: Kök Yayıncılık.

Barton, E.E. \& Joseph, B.J. (2015). The Prescool inclusion toolbox. Baltimore: Paul H. Brookes Publishing. 
Büyüköztürk, Ş. (2016). Deneysel desenler. Ankara: Pegem Akademi.

Çorlu, Z. \& Ersoy, G. (2013). Okullarda destek eğitim odası açma kılavuzu. Ankara: Gölbaşı Rehberlik ve Araştırma Merkezi Müdürlüğü.

Dağlıŏlu, H. E. (2014). Okul öncesi öğretmeninin özellikleri ve okul öncesi eğitime öğretmen yetiştirme. Haktanır, G. (Ed.), Okul öncesi eğitime giriş. Ankara: Anı Yayıncılık.

Dikici Sığırtmaç, A. \& Deretarla, G. E. (2012). Okul öncesinde özel eğitim. Ankara: Kök Yayıncılık.

Espinosa, L.M. (2002). High-Quality PreSchool: Why we need it and what it looks like. NIEER Preschool Policy Matters 1. Erişim adresi: https://files.eric.ed.gov/fulltext/ED480816.pdf

Guralnick, M.J. \& Bruder, M.B.(2016). Early childhood inclusion in the United States: Goals, current status, and future directions Infants \& Young Children 29 3, 166-177. Erişim adresi: https://depts.washington.edu/chdd/guralnick/pdfs/2016-Guralnick_Bruder-

Early_Childhood_Inclusion.pdf

Gürbüz, S. \& Şahin, F. (2016). Sosyal bilimlerde araştırma yöntemleri felsefe yöntem ve analiz. Ankara: İvogsan.

Hu, B.Y., Mak, M.C.K., Zhang, C., Fan, X. \& Zhu, J. (2018). Chinese parents' beliefs about the importance and feasibility of quality early childhood inclusion, International Journal of Disability, Development and Education, 65 2, 163-182, DOI: 10.1080/1034912X.2017.1358809

Ilgar, Z. (2006). Çocuklarda hareket gelişsimi ve eğitimi. Erzurum: Ilgar Eğitimcilik ve Yayıncılık.

İlköğretim ve Eğitim Kanunu. (1961, 31 Mayıs). Resmi Gazete (Sayı: 10816). Erişim adresi: https://www.resmigazete.gov.tr/arsiv/10816.pdf

Justice, L.M., Logan, J.R., Tzu-Jung, L. \& Kaderavek, J.N. (2014). Peer effects in early childhood education: Testing the assumptions of special education inclusion. Psychological Science, $25,1722-1729$.

Karasar, N. (2005). Bilimsel araştırma yöntemleri. Ankara: Nobel Yayıncılık.

Kırcaali İftar, G. (1998). Kaynaştırma ve destek özel eğitim hizmetleri. Eripek, S. (Ed.). Özel eğitim. Eskişehir: Anadolu Üniversitesi Açık Öğretim Fakültesi Yayınları. Erişim adresi: https://www.academia.edu/7508845/ANADOLU_\%C3\%9CN\%C4\%B0VERS\%C4\%B0TE S\%C4\%B0_A\%C3\%87IK\%C3\%96GRET\%C4\%B0M_FAK\%C3\%9CLTES\%C4\%B0

Kış, H. (2013). Destek eğitim odalarındaki uygulamalara ilişkin rehber ögrretmenler ve özel eğitim sınıf öğretmenlerinin görüşleri (Yayımlanmamış yüksek lisans tezi). Abant İzzet Baysal Üniversitesi, Bolu.

Kutluca Canbulat, A. (2010). Okula destek eğitiminin etkililiği (Yayımlanmamış doktora tezi). Abant İzzet Baysal Üniversitesi, Bolu.

Milli Eğitim Bakanlığı [MEB], (2008). Kaynaştırma Yoluyla Eğitim Uygulamaları. Özel Eğitim ve Rehberlik Hizmetleri Müdürlüğü, 2008/60, 02 Eylül 2008. Erişim adresi: https://orgm.meb.gov.tr/meb_iys_dosyalar/2015_10/08101631_kaynatrmayoluylaeitimuyg ulamasgenelgesi.pdf

Milli Eğitim Bakanlığı [MEB], (2013). Okul öncesi eğitim programı. Ankara: MEB Yayınları.

MEGEP (2011). Çocuk Gelişimi ve eğitimi. Erken Çocukluk İlkelerinde Temel İlkeler, Ankara: MEGEP Yayını, 141EO0039. Erişim adresi: 
http://www.megep.meb.gov.tr/mte_program_modul/moduller_pdf/Erken\%20\%C3\%87ocu kluk\%20E\%C4\%9Fitiminde\%20Teme1\%20\%C4\%B0lkeler.pdf

Özel Eğitim Hizmetleri Yönetmeliği. (2018, 7 Temmuz). Resmi Gazete (Sayı: 30471). Erişim adresi: https://orgm.meb.gov.tr/meb_iys_dosyalar/2018_07/09101900_ozel_egitim_hizmetleri_yo netmeligi_07072018.pdf

Strain, P.S. \& Bovey II, E.H. (2011). Randomized, controlled trial of the LEAP model of early intervention for young children with autism spectrum disorders. Topics in Early Childhood Special Education 313 133-154, DOI: 10.1177/0271121411408740

Sukumaran, S., Loveridge, J. \& Green, V.A. (2015). Inclusion in Malaysian integrated preschools, International Journal of Inclusive Education, 19 8, 821-844, DOI: $10.1080 / 13603116.2014 .981229$

Ültay, E. \& Ültay, N. (2016). Okul öncesi eğitim için öğretim teknikleri ve materyal geliştirme. Ankara: Almat Basım Yayıncılık.

Ünal, H. (2008). Birlikte eğitim ortamındaki zihinsel yetersizlikten etkilenmiş ögrencilere destek eğitim odasında verilen destek eğitimin etkililiği (Yayımlanmamış yüksek lisans tezi). Gazi Üniversitesi, Ankara.

Ünay, E. (2012). Bireysel destek ĕgitiminin kaynaştırma ögrrencilerinin matematik başarıları ve öz yeterlilik algıları üzerindeki etkileri (Yayımlanmamış doktora tezi). Dokuz Eylül Üniversitesi, İzmir.

Tunalı Erkan, D. (2018). Ortaöğretim kurumlarındaki destek eğitim odası uygulamasına ilişkin öğretmen görüşleri, Uluslararası Liderlik Eğitimi Dergisi(ULED), 2(2), 17-30. 